\title{
Serum interleukin 5 concentrations in atopic and non-atopic patients with glucocorticoid- dependent chronic severe asthma
}

\author{
Andrew G Alexander, Julia Barkans, Redwan Moqbel, Neil C Barnes, A Barry Kay, \\ Christopher J Corrigan
}

\begin{abstract}
Background -Interleukin (IL)-5 is thought to play a part in asthmatic bronchial mucosal inflammation and is a potential therapeutic target. Detectable serum IL-5 concentrations have been found previously in a proportion of patients with acute severe asthma, but not in the same patients following oral glucocorticoid therapy or in normal controls. A study was undertaken to investigate whether or not IL-5 is detectable in the serum of patients with glucocorticoid-dependent chronic severe asthma.
\end{abstract}

Methods - Serum concentrations of IL-5 were measured in 29 patients with stable oral glucocorticoid-dependent chronic severe asthma (mean PEFR $59.7 \%$ predicted) and seven normal controls using a specific enzyme-linked immunoassay calibrated with recombinant human IL-5 standards (lower limit of sensitivity $40 \mathrm{pg} /$ ml).

Results - Interleukin 5 was detectable in the serum of 15 of the 29 patients at a median concentration of $150 \mathrm{pg} / \mathrm{ml}$ (range 40-690), but was undetectable in the serum of all the control subjects. The patients with detectable serum IL -5 concentrations did not differ from those with undetectable concentrations in terms of atopic status, disease severity (percentage predicted PEFR or FEV $_{1}$ ), prednisolone dosage, serum IgE concentrations, or peripheral eosinophil count.

Department of Allergy and Clinical Immunology, National Heart and Lung Institute, London SW3 6LY

A G Alexander

J Barkans

R Moqbel

A B Kay

C J Corrigan

Department of

Thoracic Medicine,

London Chest

Hospital, London

E2 90X

N C Barnes

Reprint requests to: Professor A B Kay.

Received 9 June 1994 Returned to authors 28 July 1994

Revised version received Revised version rece
19 August 1994

19 August 1994
Accepted for publication

6 September 1994
Conclusions - Interleukin 5 is detectable in the serum of a proportion of both atopic and non-atopic patients with chronic severe asthma, and concentrations in these patients were higher than in normal controls. These observations are compatible with the hypothesis that IL-5 release occurs in these patients during a period of stable asthma despite systemic glucocorticoid therapy.

(Thorax 1994;49:1231-1233)

There is increasing evidence that the eosinophil-rich bronchial inflammation characteristic of asthma is orchestrated, at least partly, by cytokine products of activated CD4 $T$ lymphocytes. Of these, interleukin (IL)- 5 is particularly implicated because, together with IL-3 and granulocyte/macrophage colony stim- ulating factor, it promotes the differentiation, priming, and survival of eosinophils in vitro. ${ }^{1}$ Interleukin 5 has also been clearly implicated in the pathogenesis of asthma from in vivo studies. Increased IL-5 mRNA expression was observed in bronchial mucosa ${ }^{2}$ and in bronchoalveolar lavage fluid cells ${ }^{3}$ from mild atopic asthmatics compared with controls. The degree of expression correlated with disease severity and symptomatology.

We have previously shown that peripheral blood CD4 T lymphocyte activation is accompanied by raised serum concentrations of IL-5 in a proportion of both atopic and nonatopic patients with acute severe asthma, but that IL-5 was not detectable in the same patients following oral glucocorticoid therapy, or in normal controls. ${ }^{4}$ Others have reported raised plasma concentrations of soluble IL2 receptor in oral glucocorticoid-dependent asthmatics compared with patients controlled without oral glucocorticoids, suggesting that ongoing $\mathrm{T}$ lymphocyte activation is associated with severe chronic disease despite maintenance prednisolone. ${ }^{5}$ The aim of this study was to investigate whether IL-5 may be implicated in the pathogenesis of oral glucocorticoid-dependent chronic severe asthma.

\section{Methods}

Documented chronic asthmatic subjects aged 18-65 years with $\mathrm{FEV}_{1}$ and/or PEFR below $75 \%$ of the predicted value and $>20 \%$ reversibility to $\beta_{2}$ agonist were considered for the study if they required long term maintenance treatment with $5-20 \mathrm{mg}$ oral prednisolone daily, in addition to maximal tolerated and effective other therapy including high dose inhaled glucocorticoids. Written informed consent was obtained from each patient and the study was approved by the ethics committee of the Royal Brompton National Heart and Lung Hospitals.

A total of 11 men and 18 women aged 21-62 (mean 49) years who had had asthma for 5-54 (mean 29) years and had received continuous treatment with oral prednisolone for 0.5-26 (mean 9.7) years were enrolled. Mean (SE) daily dosage of prednisolone was $8.6(0.8) \mathrm{mg}$ and of inhaled glucocorticoid was 1630 (99) $\mu \mathrm{g}$; median (range) total serum IgE concentration was $76(6-1250) \mathrm{IU} / \mathrm{ml}$ and peripheral blood eosinophil count $0.2(0-1 \cdot 2) \times 10^{9} / 1$. Twenty of the patients studied were atopic (as defined by one or more positive skin prick tests to 


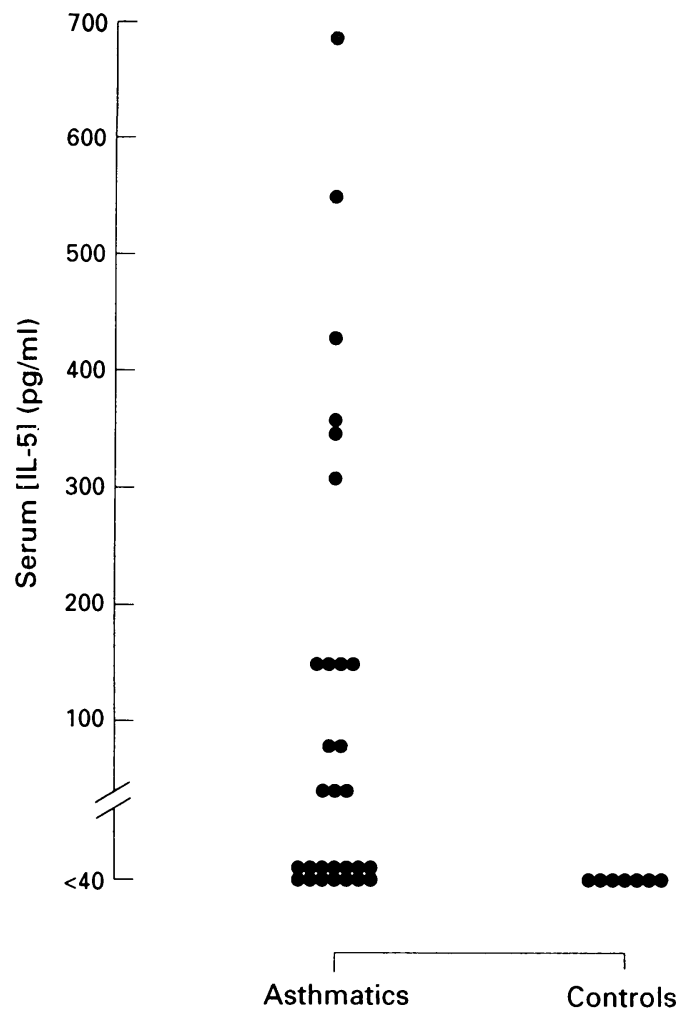

Figure 1 Serum concentrations of interleukin 5 in patients with glucocorticoid-dependent chronic severe asthma and in normal controls. with oral theophylline. A group of seven normal healthy volunteers aged 21-46 (mean 30) years with no known diseases and taking no medication was also studied. Mean (SE) FEV 1 was $100(2 \cdot 7) \%$ predicted and three subjects were atopic.

Patients recorded PEFR measurements on diary cards at home during a four week period. Those who had a disease exacerbation requiring an increase in prednisolone dosage were excluded, ensuring that all patients had been stable on their usual maintenance prednisolone dosage during the four week study period. At the end of this period $\mathrm{FEV}_{1}$ was measured in the clinic and a peripheral venous blood sample was obtained for measurement of whole blood eosinophil count and serum IL-5 concentration. Mean morning prebronchodilator PEFR for the four week period and $\mathrm{FEV}_{1}$ (best of three values) were expressed as percentages of the predicted values. Mean (SE) PEFR was 276 (21) $1 / \mathrm{min}\left(59 \cdot 7 \%\right.$ predicted) and $\mathrm{FEV}_{1}$ $1.93(0.19) 1(66.9 \%$ predicted $)$. Serum concentrations of IL-5 were measured in duplicate in the same assay using a specific enzymelinked immunoassay calibrated with recombinant human IL-5 standards (lower limit of sensitivity $40 \mathrm{pg} / \mathrm{ml}$ ) which has been described in detail elsewhere. ${ }^{6}$

\section{Results}

Interleukin 5 was detectable in the serum of 15 of the 29 asthmatic patients at a median concentration of $150 \mathrm{pg} / \mathrm{ml}$ (range 40-690) but was undetectable in the serum of all the control subjects (fig 1). There were no significant differences (Mann-Whitney U test) between the patients with and without detectable serum concentrations of IL-5 with regard to atopic status (fig 2), disease severity (percentage predicted PEFR or $\mathrm{FEV}_{1}$ ), prednisolone dosage, serum IgE concentration, peripheral eosinophil count, or theophylline usage.

\section{Discussion}

Interleukin 5 has not previously been identified in patients with chronic severe asthma. We have previously shown that serum IL-5 concentrations were raised $(200-1500 \mathrm{pg} / \mathrm{ml})$ in $53 \%$ of a group of patients with acute severe asthma, but that IL-5 was undetectable following seven days of treatment with oral prednisolone. ${ }^{4}$ The present finding that, compared with normal controls, the concentration of IL5 was increased in the serum of $52 \%$ of these patients during a period of stable asthma is compatible with the hypothesis that IL-5 release is occurring in these patients despite oral glucocorticoid therapy. The detection of IL-5 in atopic and non-atopic patients with mild, ${ }^{23}$ acute severe, and chronic severe asthma is compatible with a common pathogenetic role for IL-5 in asthma.

Little is known about cytokine metabolism in vivo and several factors may explain the variability in serum IL-5 concentrations. These include the inability of the assay to detect a range of 12 common aeroallergens in the presence of a positive histamine control and a negative vehicle control) and 20 were treated 
concentrations lower than $40 \mathrm{pg} / \mathrm{ml}$, variable clearance from the circulation as well as variable release, the range of prednisolone dosage, and the unknown effects of circulating soluble IL5 receptors. The presence of IL-5 within the bronchial mucosa, which might be more relevant to the pathogenesis of asthma, may therefore not be closely reflected by its presence in peripheral blood. This, in addition to the relatively small patient numbers, may explain why - in contrast to the findings in mild asthma in which the degree of IL-5 mRNA expression in bronchial mucosa and bronchoalveolar lavage fluid correlated with disease severity - no relation was seen between serum concentrations of IL-5 and disease severity in either the acute or chronic severe patients.
The authors thank Glaxo for the gift of the TRFK5 antibody.

1 Kay AB. Asthma and inflammation. 7 Allergy Clin Immunol 1991;87:893-910.

2 Hamid O, Azzawi M, Sun Ying, Mogbel R, Wardlaw AJ, Corrigan CJ et al. Expression of mRNA for interleukin-5 in mucosal bronchial biopsies from asthma. $\tilde{f}$ Clin Invest 1991;87:1541-6.

3 Robinson DS, Hamid Q, Sun Ying, Tsicopoulos A, Barkans $\mathrm{J}$, Bentley AM, et al. Predominant $\mathrm{T}_{\mathrm{H} 2}$-like bronchoalveolar T-lymphocyte population in atopic asthma. $N$ Engl f Med 1992;326:298-304.

4 Corrigan CJ, Haczku A, Gemou-Engesaeth V, Doi S, Kikuchi Y, Takatsu K, et al. CD4 T-lymphocyte activation in asthma is accompanied by increased serum conin asthma is accompanied by increased serum conapy. Am Rev Respir Dis 1993;147:540-7.

5 Lassalle P, Sergant M, Delneste Y, Gosset P, Wallaert B, Zandecki $M$, et al. Levels of soluble IL-2 receptor in plasma from asthmatics. Correlations with blood eosinophilia, lung function, and corticosteroid therapy. Clin Exp Immunol 1992;87:266-71.

6 McNamee LA, Fattah DI, Baker TJ, Bains SK, Hissey PH. Production, characterisation and use of monoclonal antibodies to human interleukin-5 in an enzyme-linked immunosorbent assay. F Immunol Methods 1991;141:81-8. 